\title{
TOPICAL ANAESTHESIA FOR PHACOEMULSIFICATION SURGERY
}

\author{
I. G. M. DUGUID, C. M. P. CLAOUÉ, Y. THAMBY-RAJAH, B. D. S. ALLAN, J. K. G. DART and \\ A. D. McG. STEELE \\ London
}

\begin{abstract}
SUMMARY
Although phacoemulsification with only topical anaesthesia is possible, the level of any discomfort perceived by the patient is unknown. Topical anaesthesia eliminates any risk of inadvertent ocular or orbital injury. Twenty-four patients undergoing phacoemulsification under only topical anaesthesia (g. amethocaine $1 \%)$ were compared with 23 patients undergoing the same procedure with peribulbar anaesthesia $(5 \mathrm{ml}$ lignocaine $2 \%, 5 \mathrm{ml}$ bupivacaine $0.5 \%$ and 75 units hyaluronidase). Perceived pain on administration of the anaesthesia, per-operatively and post-operatively was assessed by a nursing officer using a visual analogue scale (0-10). It was found that there was no difference in pain score between the two groups on induction of anaesthesia. Per-operatively and post-operatively scores were higher in the topical group than in the peribulbar group $(p<0.05$, Mann-Whitney $U$-test $)$, though most of these were within the range $0-3$, ('no pain' to 'slight pain'). There was no difference in the amount of analgesia dispensed to the two groups on the ward post-operatively. In conclusion, topical anaesthesia provides adequate anaesthesia for phacoemulsification. Although a small increase in the level of discomfort was observed, the pain levels reported were small and may not be clinically significant when set against the reduced incidence of anaesthetic-related complications.
\end{abstract}

With the advent of phacoemulsification, cataract surgery using only topical anaesthesia has become a reality. ${ }^{1}$ This form of anaesthesia has several advantages over regional infiltrative techniques, such as peribulbar, retrobulbar and sub-Tenon injection, the foremost of which is the abolition of any risk of inadvertent injury to the globe or orbital contents ${ }^{2}$ The drops are applied just a few minutes before surgery and anaesthesia is sufficient to perform phacoemulsification through a scleral or

Correspondence to: Mr Graham Duguid, Moorfields Eye Hospital, City Road, London EC1V 2PD, UK. corneal pocket, with or without a superior rectus suture, typically with a single dose.

During our initial experiences with topical anaesthesia for phacoemulsification, it became clear that the patients were usually aware of 'a sensation' during surgery. This was not reported as unacceptably painful by the patients but warranted further investigation. This study aimed to investigate that level of pain perceived by patients undergoing surgery under topical anaesthesia, in comparison with the peribulbar technique.

\section{MATERIALS AND METHODS}

Study Population

Forty-seven consecutive patients (32 women, 15 men) undergoing phacoemulsification under local anaesthesia as an outpatient under two consultant teams were studied. One team (A.D.McG.S. and C.M.P.C.) used only topical anaesthesia and the other (J.K.G.D., B.D.S.A. and I.G.M.D.) used peribulbar anaesthesia.

\section{Topical Anaesthesia}

Topical anaesthesia was administered to one group in the form of 6 drops $\mathrm{g}$. amethocaine $1 \%$ (preservative free) instilled to the superior conjunctival fornix once the patient was positioned on the operating table. The patient was asked to report when the stinging sensation subsided. The surgeon then scrubbed and surgery commenced. Additional drops were applied prior to the subconjunctival injection.

\section{Peribulbar Anaesthesia}

Peribulbar anaesthesia consisted of $10 \mathrm{ml}$ of a 50:50 mixture of lignocaine $2 \%$ and bupivacaine $0.5 \%$ with 75 units of hyaluronidase. This was divided between two injections: the first through the inferotemporal conjunctiva and the second medial to the lacrimal caruncle. A mercury bag was applied until the patient went into theatre. 


\section{Surgical Technique}

After standard aseptic preparation and draping, a wire speculum was inserted and a superior rectus bridle suture used where necessary. A temporal corneal pocket was used if access was considered difficult due to a prominent superior orbital margin or in the presence of against-the-rule astigmatism. Otherwise a superior scleral pocket was used. The remaining surgery was constant in all cases: $2 \%$ hydroxymethylcellulose was instilled into the anterior chamber, a curvilinear capsulorhexis and hydrodissection performed, the lens nucleus removed by endolenticular phacoemulsification using a fourquadrant nucleus cracking technique where possible, the remaining cortex aspirated, a foldable posterior chamber intraocular lens inserted through the $4 \mathrm{~mm}$ incision, the HPMC removed, approximate physiological pressure restored with balanced-salt solution through the side-port and the section confirmed watertight. The patients were warned that they might experience some pain prior to the subconjunctival injection of $4 \mathrm{mg}$ betamethasone and antibiotic (125 mg cefuroxime or $10 \mathrm{mg}$ gentamicin) which was injected inferiorly.

\section{Pain Assessment}

Pain assessment was carried out on return to the daycare ward by the same member of the nursing staff (Y.T.-R.), who had not met any of the patients

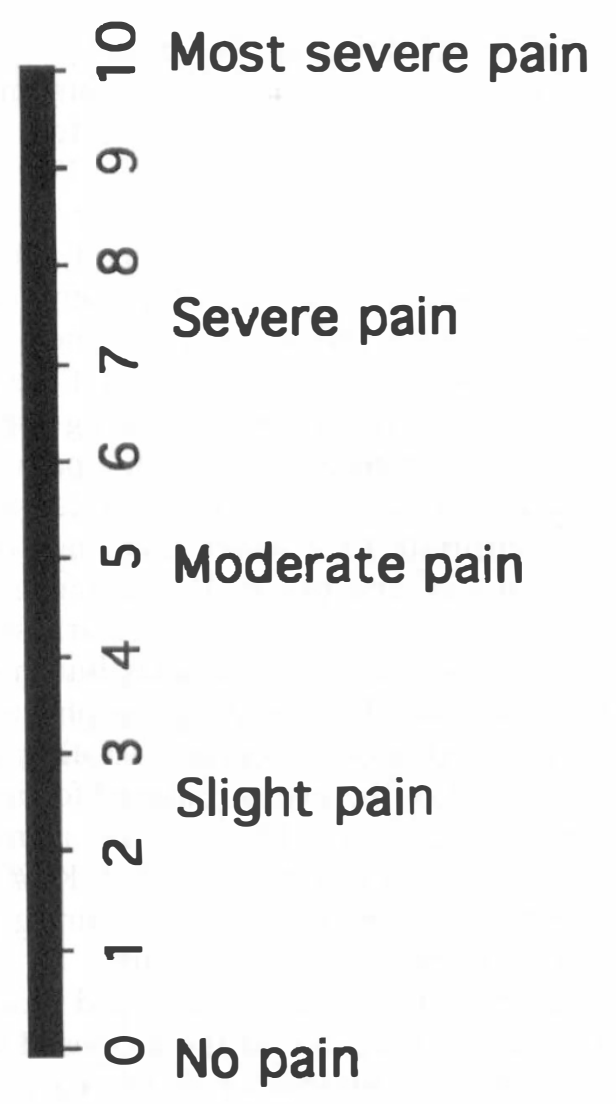

Fig. 1. The visual analogue pain scale. before. The patients were asked to grade any pain felt on a standard $10 \mathrm{~cm}$ visual analogue scale, 0 representing no pain at all, 10 representing the most severe pain imaginable (Fig. 1). All patients were asked to grade pain perceived at three stages of the procedure: at induction (i.e. instillation of the drops or the peribulbar injection), per-operatively, and 1 hour post-operatively at the time of assessment in the ward. Any analgesia given was also recorded. The questions were phrased identically to all patients. Additionally the surgeon was asked to report any difficulty encountered attributable to the operating conditions. The pain scores for each group were compared using the Mann-Whitney $U$-test for nonparametric statistics.

\section{RESULTS}

The topical anaesthetic group comprised 24 patients ( 8 men, 16 women) with mean age of 63 years (range 30-84 years). The peribulbar anaesthetic group comprised 23 patients ( 7 men, 16 women) of mean age 69 years (range $44-89$ years). In no case did the surgeon operating report unfavourable operating conditions attributable to the anaesthesia, nor did surgery have to be abandoned or intravenous sedation or analgesia given.

Fig. 2 shows the distribution of pain scores at the induction of anaesthesia. Scores ranged from 0 to 7 in the topical group and from 0 to 10 in the peribulbar group. There was no significant difference between the pain perceived with instillation of topical drops and that with peribulbar injection.

Fig. 3 shows the pain scores pre-operatively. Scores ranged from 0 to 5 in both patient groups. The

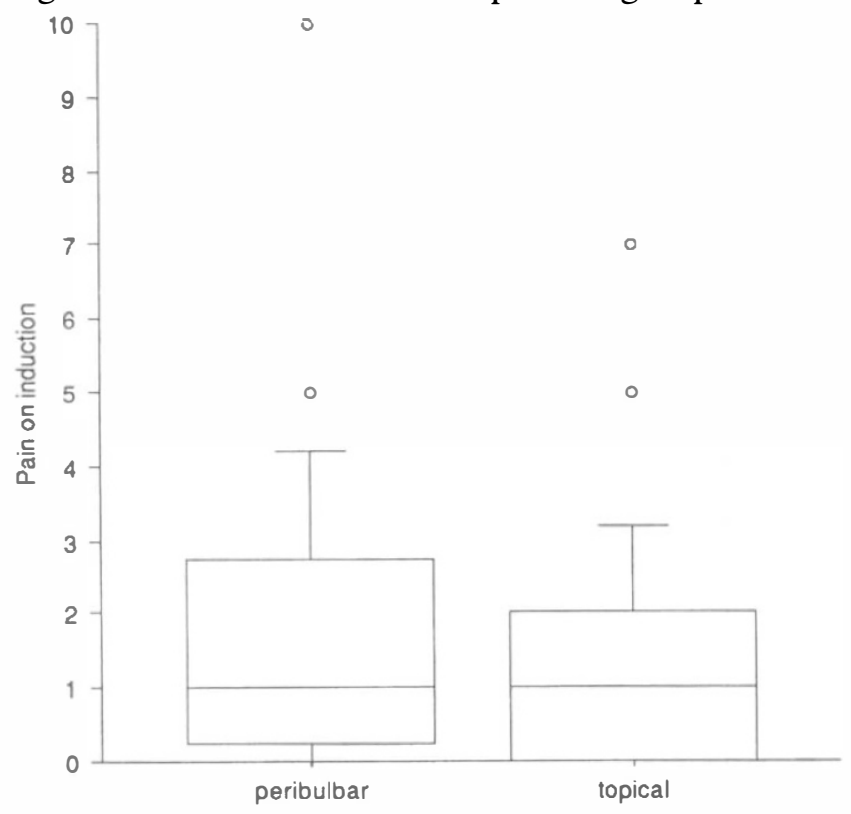

Fig. 2. Pain scores on induction. Box plots show range of $50 \%$ of the responses with the median as the horizontal line; bars show $80 \%$ of the range, with any response outwith this range shown as a circle (NS, Mann-Whitney U-test). 


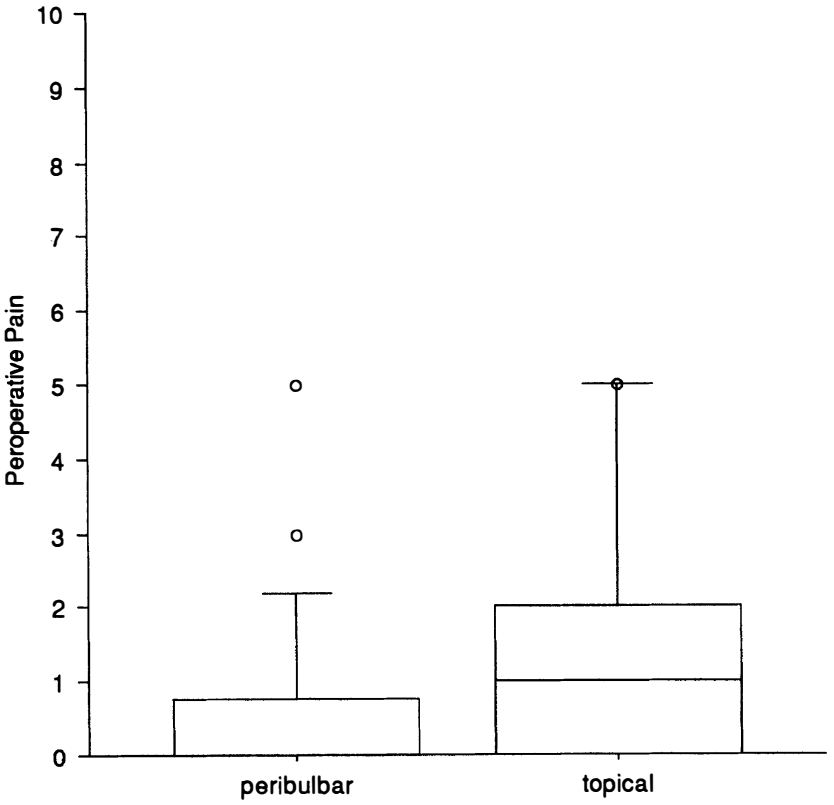

Fig. 3. Box plot of per-operative pain scores $(\mathrm{p}<0.05)$.

median scores were 0 for the peribulbar group and 1 for the topical group, and most of the scores in each group represented 'slight pain' or less. The scores were significantly higher in the topically anaesthetised patients $(p<0.05)$.

Fig. 4 shows the pain scores post-operatively. Scores ranged from 0 to 5 for the topical group and from 0 to 3 in the peribulbar group. The median scores were 0 for the peribulbar group and 1 for the topical group, and most of the scores in each group again represented 'slight pain' or less. The scores were significantly higher for the topical group

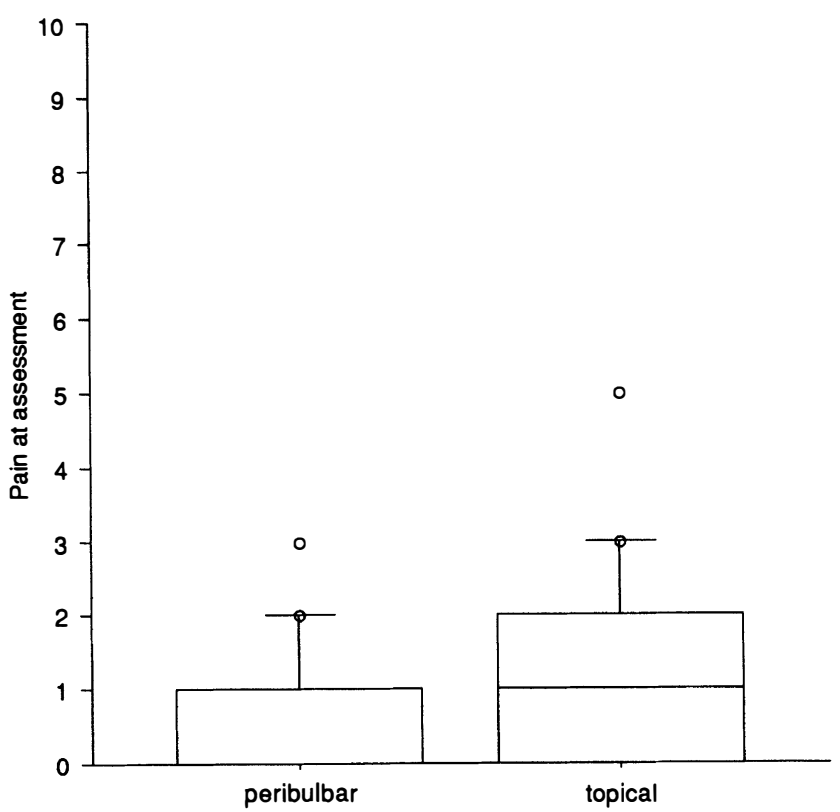

Fig. 4. Box plot of pain scores at time of assessment on return to ward (NS).
Table I. Summary of advantages and disadvantages of topical anaesthesia over peribulbar or retrobulbar anaesthesia

\begin{tabular}{ll}
\hline Advantages & \multicolumn{1}{c}{ Disadvantages } \\
\hline $\begin{array}{l}\text { No risk of globe perforation } \\
\text { No risk of damage to orbital } \\
\text { contents (vessels, optic nerve, }\end{array}$ & $\begin{array}{l}\text { Ocular motility persists } \\
\text { No iris anaesthesia } \\
\text { Greater degree of patient } \\
\text { cooperation required }\end{array}$ \\
$\begin{array}{l}\text { No chem of subdural injection } \\
\text { No pre-operative intraocular pressure rise } \\
\text { No post-operative diplopia } \\
\text { Reduced risk of cardiac arrhythmia } \\
\text { Lower cost }\end{array}$ \\
More rapid induction and recovery \\
\hline
\end{tabular}

$(p<0.05)$. Only 2 patients in the peribulbar group and 3 in the topical group required analgesia on the ward.

\section{DISCUSSION}

Topical anaesthesia in the form of $5 \%$ cocaine was described as 'pre-eminently useful' for cataract extraction by Knapp in $1884 .^{3} \mathrm{He}$ reported that pain was felt only when the iris was grasped to perform an iridectomy. Nucleus expression is likely to produce pain due to stretching of the iris, particularly where dilatation is poor. By fragmenting the nucleus in situ, phacoemulsification obviates the need to touch the iris during cataract extraction, provided the pupil is well dilated.

Cataract surgery under topical anaesthesia requires full cooperation of the patient during the procedure to prevent undesirable movement of the globe, and this requires particular effort by the surgeon to win the patient's confidence. The surgeon may, however, use the persisting ocular motility to advantage if superior access is difficult. The wirespeculum is sufficient to prevent significant lid twitching with each blink of the other eye. A superior rectus suture is easily inserted if the patient is asked to look inferiorly. Occasionally grasping the superior rectus seemed to induce some pain. Such a bridle suture may be omitted in most cases, which may well contribute to a lower incidence of postoperative diplopia ${ }^{4}$ and ptosis. The patient needs to be asked to try to keep the eye particularly still for a moment to perform the capsulorhexis, but thereafter the globe is adequately fixated by the phacoemulsification probe and nucleus rotator. Another request for no movement of the eye is required for insertion of the intraocular lens. The use of a modified Thornton ring (Duckworth \& Kent, UK \# 9-502) also facilitates control of the globe during phacoemulsification without a fixation suture.

The ideal anaesthetic technique should produce an adequate level of analgesia for the proposed surgical procedure, inflict the minimum pain or toxicity on the patient and be performed easily. Whilst both the 
peribulbar and retrobulbar techniques are effective $e^{5}$, there is a small risk of globe perforation $\left(0.006 \%^{6}\right)$, retrobulbar haemorrhage $\left(0.072 \%^{3}\right)$ and damage to extraocular structures (e.g. extraocular muscles) with these. A subdural injection may also occur with retrobulbar injection, which may result in brain-stem anaesthesia or death. ${ }^{7}$ Optic atrophy, and central retinal vein and central retinal artery occlusion have also been reported. ${ }^{8}$ Most of these risks are eliminated by the use of a sub-Tenon's injection as described by Stevens. ${ }^{9}$ This technique is effective, but still requires the injection of a relatively large amount of anaesthetic agent into the orbit. This may distort the fascial planes and the small risk of retrobulbar haemorrhage or cardiac arrhythmia through systemic absorption remains.

Topical anaesthesia is rapid and straightforward to perform. It is also likely to be more acceptable to patients, a large proportion of whom are afraid of needles. There is no risk of damage to the globe or orbital contents and therefore topical anaesthesia is strongly indicated in the presence of large, staphylomatous globes, scleritis, and a systemic or drugassociated bleeding tendency. The absence of akinesia, whilst increasing the technical difficulty for the surgeon, also avoids any transient postoperative diplopia experienced by the patient compared with any regional anaesthetic block. Diplopia may still occur if the cataract has impaired the patient's fusion. ${ }^{4}$ The mydriasis and cycloplegia are now the limiting factors on immediate optimum post-operative vision. Finally the cost of each anaesthetic is less for topical amethocaine than for the lignocaine, bupivicaine and hyaluronidase mixture (£0.34 compared with $£ 3.27$ respectively at current local prices, assuming a vial of hyaluronidase is diluted and used for 5 cases on a list.)

Significant pain may be associated with the subconjunctival injection at the end of the operation in patients anaesthetised with both topical and peribulbar techniques. There was no doubt that this part of the procedure could be improved, and additional amethocaine is now routinely applied over the proposed site of injection. It may be possible to omit subconjunctival injection altogether. $^{10}$

A reasonable degree of experience is required to perform phacoemulsification under topical anaesthesia. The capsulorhexis has to be performed quickly to minimise the risk of an unfavourable effect of patient movement. One must avoid touching the unanaesthetised iris with any instruments, and the risk of per-operative miosis is minimised by efficient phacoemulsification. Having said this, the topical anaesthesia proved adequate for additional anterior vitrectomy required to deal with the one case in which posterior capsule rupture occurred. Should topical anaesthesia prove to be inadequate in any case, the self-sealing incision allows safe intraoperative conversion to peribulbar or retrobulbar anaesthesia, although this has never been required in our experience.

In conclusion, this study shows that topical anaesthesia results in adequate analgesia for phacoemulsification, although a slightly higher level of per-operative discomfort is perceived. However, since this is described as less than 'slight pain' on a visual analogue scale, its clinical significance has to be weighed against the complete absence of sight- or life-threatening complications with this technique.

Key words: Cataract surgery, Pain, Topical anaesthesia, Visual analogue scale.

\section{REFERENCES}

1. Grabow HB. Topical anaesthesia for cataract surgery. Eur J Implant Refract Surg 1993;5:20-4.

2. Hamilton RC, Gimbel HV, Javitt JC. The prevention of complications of regional anaesthesia for ophthalmology. In Zahl K, Keltzer MA (eds). Ophthalmology clinics of North America, vol 3. Regional anaesthesia for intraocular surgery. Philadelphia: WB Saunders, 1990:111-25.

3. Knapp $H$. On cocaine and its use in ophthalmic surgery. Arch Ophthalmol 1884;13:402-48.

4. Wylie J, Henderson M, Doyle M, Hickey-Dwyer M. Persistent binocular diplopia following cataract surgery: aetiology and management. Eye 1994;8:543-6.

5. Murdoch IE. Peribulbar versus retrobulbar anaesthesia. Eye 1990;4:445-9.

6. Davis DB, Mandel MR. Efficacy and complication rate of 16224 consecutive peribulbar blocks. J Cataract Refract Surg 1994;20:327-37.

7. Hamilton RC. Brain stem anaesthesia following retrobulbar blockade. Anaesthesiology 1985;63: 688-90.

8. Berry CB, Murphy PM. Regional anaesthesia for cataract surgery. Br J Hosp Med 1993;49:680-701.

9. Stevens JD. A new local anaesthesia technique for cataract extraction by one quadrant sub-Tenon's infiltration. Br J Ophthalmol 1992;76:670-4.

10. Sanders R, MacEwen CJ, Haining WM. A comparison of prophylactic, topical and subconjunctival treatment in cataract surgery. Eye 1992;6:105-10. 